\title{
Hepatitis C Virus Prevalence and Genotyping among Hepatocellular Carcinoma Patients in Baghdad
}

\author{
Waqar Abd Al Qahar Al-Kubaisy ${ }^{1,2}$, Kadhim Jawad Obaid ${ }^{1}$, Nor Aini Mohd \\ Noor ${ }^{1,3}$, Nik Shamsidah Binti Nik Ibrahim ${ }^{1}$, Ahmed Albu-Kareem Al-Azawi ${ }^{4}$
}

\begin{abstract}
Hepatocellular carcinoma (HCC) is the third most common cause for cancer death in the world, now being especially linked to chronic hepatitis C virus (HCV) infection. This case-control study consisting of 65 HCC patients and 82 patients with other malignant tumours as controls was conducted to determine the association of HCV markers with HCC. Serum of each participant was obtained for detection of HCV Ab and RNA by DNA enzyme immunoassay (DEIA). Twenty six per cent $(26.0 \%)$ of HCC patients had positive anti-HCV which was significantly greater than the control group $(\mathrm{p}=0.001)$. HCC patients significantly have a risk of exposure to HCV infection almost 3 times than the control group $(O R=2.87,95 \% \mathrm{C}$.I=1.1-7). Anti-HCV seropositive rate was significantly $(\mathrm{p}=\mathbf{0 . 0 3})$ higher among old age $\mathrm{HCC}$ patients and increases with age. Males with $\mathrm{HCC}$ significantly showed to have more than 9 times risk of exposure to $\mathrm{HCV}$ infection $(\mathrm{OR}=9.375,95 \% \mathrm{CI}=1.299-67.647)$ than females. HCV-RNA seropositive rate was $(\mathbf{7 0 . 8} \%)$ significantly higher among HCC patients compared to (22.2\%) the control group $(\mathrm{p}=\mathbf{0 . 0 1 9})$. The most prevalent genotype (as a single or mixed pattern of infection) was HCV1b. This study detected a significantly higher HCV seropositive rate of antibodies and RNA in HCC patients.
\end{abstract}

Keywords: Hepatocellular carcinoma - hepatitis C virus - HCV markers - Iraq

Asian Pac J Cancer Prev, 15 (18), 7725-7730

\section{Introduction}

Hepatocellular carcinoma (HCC) accounted for $7 \%$ of all cancers ( Aghemo and Colombo, 2013) and 80-90\% of primary liver cancer (Sangiovanni et al., 2004; Peng et al., 2012). A recent estimate indicated that HCC was the fifth and the seventh most common cancer in males, and females respectively, with a total of 560,000 new cases annually and $83 \%$ occurred in developing countries (ElSerag, 2002; Sherman 2005; Levrero, 2006; Aghemo and Colombo, 2013; Jin-Hu et al., 2013; Jen-Eing et al., 2014). HCC is the third most common cause for cancer deaths in the world (Parkin, 2005; Levrero, 2006), especially in patients with chronic hepatitis $\mathrm{C}$ virus (HCV) infection (Levrero, 2006).

It is responsible for approximately one million deaths annually. HCC is considered as one of the most common malignancies worldwide with an increasing incidence for the past decades (Jin-Hu et al., 2013). In many countries, the trend of HCC is attributed to several liver diseases including HCV infection (Sangiovanni et al., 2004; Denis et al., 2012; Jin-Hu et al., 2013) HCV affects more than 170 million individuals worldwide especially in industrialised countries (Amal et al., 2011; Tornesello et al., 2013) and thus posed a global health challenge (Nelson et al., 2011; Takeshi et al., 2012). Japan, for example, unlike other Asian countries, has a high proportion of HCC caused by HCV infection accounting for $80-90 \%$ of all cases (El-Serag and Rudolph, 2007) and in the United States (U.S) the prevalence of chronic HCV infection is now the leading cause of HCC (Altekruse et al., 2009). Several studies found a three-fold increase in HCV-related $\mathrm{HCC}$, whereas the rate of HCC associated with HBV or alcohol-induced liver disease and idiopathic cirrhosis remained stable (El-Serag and Mason, 2000; Sherman, 2005). Incidence of HCC is expected to increase in the next two decades, largely due to hepatitis $\mathrm{C}$ infection (Willatt et al., 2008). Typically, HCC only develops after several decades of infection (Rathi et al., 2011). Although the incidence of newly acquired HCV infections has decreased over the past 20 years, the incidence of $\mathrm{HCV}$-associated HCC is increasing significantly as the infected population aged (Rathi et al., 2011). Liver cancer associated with chronic HCV infection thus, will be a significant public health burden in years to come (El-Serag, 2002; Berry et al., 2005; Amal et al., 2011; Nelson et al., 2011; Rathi et al., 2011).

The rate of progression from chronic hepatitis to HCC is variable and several factors have been identified as important predictors of progression. These include factors related to the host (age at infection, gender) or environment (mode of infection) (Sherman, 2005;

${ }^{1}$ Faculty of Medicine, Universiti Teknologi MARA, Sungai Buloh Campus, Sungai Buloh, ${ }^{2}$ Drug Discovery \& Health Community of Research, Universiti Teknologi MARA (UiTM), ${ }^{3}$ Humanities and Quality of Life, Universiti Teknologi MARA (UiTM), Shah Alam, Selangor Darul Ehsan, Malaysia, ${ }^{4}$ University Hospital, Linkoping, Sweden *For correspondence: waqar_abd@yahoo.co.uk 
Savino et al., 2011), and virus (genotype/subtype, viral load) (Berry et al., 2005). A relationship was suggested between HCV genotype/subtype and serum HCV RNA levels (Anita et al., 2011).

The HCV genome has six major genotypes, and more than 70 subtypes (Lindenbach et al., 2007). The six major $\mathrm{HCV}$ genotypes vary significantly according to age, geographic location, pathological properties (Farrell, 2002) and biological response to treatment (Chayama et al., 1997; Hossein et al., 2012). As an example genotype $1 \mathrm{~b}$ is associated with rapid progression of liver damage and a less response to interferon alpha treatment (Chayama et al., 1997; Kew et al., 1997). Therefore, clinical form of HCV infection varies in different geographical areas, such as ethnic/race and environmental factors, HCV genotype and co-infection with other pathogenic agents (Lindenbach et al., 2007). Understanding the risk factors for HCC development in patients infected with $\mathrm{HCV}$ is thus of great importance for refinement of treatment strategies and healthcare delivery. Savino et al. (2011) stated that $\mathrm{HCC}$ is almost unique among cancers since the underlying cause can be identified for each patient. This is in contrast to some other major cancers, where risk factors can be identified at population level. A meaningful result for the prevention of HCC is achieved by the treatment of underlying liver diseases such as antiviral therapy for HCV (Savino et al., 2011). The pathogenesis of HCC in HCV infection has been extensively analysed. HCV induced chronic inflammation and the effects of cytokines in the development of fibrosis and liver cell proliferation are considered as one of the major pathogenic mechanism (Levrero, 2006). Several authors (David et al. 2011; Peng et al., 2012; Abd El-Rahman et al., 2013) suggested that persistent $\mathrm{HCV}$ infection and viral protein expression is likely to have a direct cancer-promoting effect.

In Iraq HCC is not uncommon, and no reports on the prevalence of anti-HCV in such patients have been published. This study was done to determine whether HCV infection is an associated risk factor among HCC patients. This study also investigated the distribution pattern of $\mathrm{HCV}$ genotypes in HCC patients, and identify whether infection with specific HCV genotypes was associated with an increased risk of HCC development.

\section{Materials and Methods}

A case-control study was conducted in Baghdad during January 2000 to February 2003. The case group consisted of 65 patients, histologically confirmed with HCC and a serum level of alpha-fetoprotein exceeding 400ng/ $\mathrm{ml}$, while 82 patients with other malignant tumours (not related to gastro intestinal system) were considered as a control group. Four hospitals namely Baghdad Teaching Hospital-Baghdad Medical City, Al Kadhmiya Teaching Hospital, Radiology and Nuclear Medicine Institute and Al Yarmuk General Teaching Hospital were chosen for data collection. Only respondents with informed consent were interviewed using a structured questionnaire and serum samples were taken for HCV markers analysis. Patients with positive serum HBV were excluded from this study. Serum sample of each participant was dispensed into two frozen vials, stored at $-20^{\circ} \mathrm{C}$ and $-70^{\circ} \mathrm{C}$ for the detection of $\mathrm{HCV}$ antibodies and RNA respectively. The presence of human antibodies in participant's (case and control groups) sera against HCV was screened using the third generation enzyme immunoassay (EIA-3 UBI, USA). Positive results of all participants were further confirmed, using third generation immunoblot assay,( Lia-Tek III) (Organon-Belgium). Only Lia-Tek III reactive serum sample was considered as positive HCV antibodies serum. All the Lia-Tek III positive anti-HCV sera (stored at $-70^{\circ} \mathrm{C}$ ) of participants were transferred to laboratories of Sorin Diagnostica (Sallugia, Italy) for molecular analysis using the RT-PCR and DNA enzyme immunoassay (DEIA) method. Each sample was subjected to extraction of RNA followed by synthesis of complementary DNA (cDNA), subsequently amplification of newly synthesized cDNA was carried out. Detection of RNA and genotypes of HCV was done using DEIA method. This method is based on hybridization of the complementary (cDNA) with a single standard DNA probe coated on the wall of the microtiter plate wells with streptavidin-biotin band. Detection of hybridization is achieved by the use of antidouble stranded DNA monoclonal antibody. Finally, the results were obtained by spectrophotometer. Classification was done using the Simmond's nomenclature for HCV genotypic classification as proposed by international HCV collaboration group 1994 (Simmonds et al.,1994). All the laboratory procedures were done according to the manufacturer's instructions.Descriptive and statistical analysis using SPSS was done. Univariate analysis, Odds ratios (ORs) and 95\% CIs were calculated, considering $\mathrm{p}<0.05$ as significant. The Ethical and Review Committee in Ministry of Health Baghdad reviewed and approved the protocols of this study. Informed consent was obtained from all participants.

\section{Results}

The number of males and females in our study were 44 cases and 21 controls and 58 cases and 24 controls respectively. Most of $\mathrm{HCC}(83.1 \%)$ patients were 60 years old and above while only $11(16.9 \%)$ patients were $\leq 50$ years old. Among the control group $47.6 \%$ aged $\leq 50$ years old, and $52.4 \%$ aged $\geq 60$ years old. Of the HCC patients, $17 / 65(26.1 \%)$ showed positive reaction for anti-HCV antibodies which was significantly greater than the $9 / 82$ $(10.1 \%)$ of control group $\left(x^{2}=5.738, p=0.017\right)$. This study revealed that $\mathrm{HCC}$ patients were significantly having risk of exposure to $\mathrm{HCV}$ infection almost 3 times higher than their control group $(\mathrm{OR}=2.87,95 \% \mathrm{CI}=1.1-7.9)$ (Table 1). Anti-HCV seropositive rate was significantly higher

Table 1. Prevalence of Anti-HCV Antibodies Among Patients with HCC (Case) and Other Malignancies (Control).

\begin{tabular}{lccc}
\hline & \multicolumn{4}{c}{ Anti-HCV Seropositive } \\
Patients & Positive & Negative & TOTAL \\
\hline HCC & $17(26.1)$ & 48 & 65 \\
Other malignancies & $9(10.97)$ & 73 & 82 \\
Total & 26 & 121 & 147 \\
\hline$* x^{2}=5.73 ; p=0.017 ; 0 R=2.87,95 \%$ &
\end{tabular}


among old age HCC patients $\left(\mathrm{x}^{2}=6.973, \mathrm{p}=0.031\right)$. Anti-HCV rate increased steadily $(9.1 \%$ for $\leq 50$ years, $17.2 \%$ for $60-69$ years and $44 \%$ for $\geq 70$ years) with age. On the other hand, such pattern was not recorded among the control groups $\left(\mathrm{x}^{2}=1.419, \mathrm{p}=0.575\right)$ (Table 2$)$. Significantly higher rate of anti-HCV seropositive was shown among 15/44 male patients (34.1\%) with HCC than among $2 / 21$ females $(9.5 \%)\left(x^{2}=4.442, p=0.035\right)$.

Males with HCC were significantly showed to have more than 9 times risk of exposure to $\mathrm{HCV}$ infection $(\mathrm{OR}=9.375,95 \% \mathrm{CI}=1.3-67.6)$ than females. On the other hand gender of the patients in the control group showed no significant association with the rate of antiHCV $\left(x^{2}=3.375, p=0.066\right)$ (Table 2). Specific HCV-RNA seropositive rate was significantly higher (12/17 or $70.8 \%)$ among HCC patients compared to the control group ((2/9 or $22.2 \%)\left(\mathrm{x}^{2}=5.539 ; \mathrm{p}=0.019\right)$. HCC patient's sera with positive HCV-RNA were significantly 9 times greater than patients in the control group $(\mathrm{OR}=9.057,95 \% \mathrm{CI}=1.9$ 42.1) (Table 3). The HCV genotype was determined in all HCV-RNA positive sera. The most prevalent genotype (as a single or mixed pattern of infection) was HCV$1 \mathrm{~b}$, which was detected in 9 patients $(64.3 \%)$ followed by HCV-4 which was detected in the sera of 7 patients $(50.0 \%)$ only. No significant difference in the rate of $\mathrm{HCV}$ genotype between case and control groups was detected. Interestingly two third $(66.7 \%)$ of $\mathrm{HCC}$ cases $(8 / 12)$ were infected with HCV-1b and (50\%) 6/12 infected by genotype $\mathrm{HCV}-4$.

\section{Discussion}

Hepatocellular carcinoma (HCC), accounted for more than $5 \%$ of cancers globally, and ranked as the 6 th most common cancer and the $3^{\text {rd }}$ leading cause of cancer-related deaths worldwide (El-Serag and Rudolph, 2007; Yang

Table 2. Demographic Profile of Patients with HCC (case) and Other Malignant Tumours (control) with Positive Anti-HCV Antibodies

\begin{tabular}{|c|c|c|c|c|c|c|}
\hline \multirow[t]{2}{*}{ Subjects } & \multirow[t]{2}{*}{ Variables } & \multicolumn{2}{|c|}{ Anti-HCV } & \multirow{2}{*}{${ }^{X^{2}}$} & \multirow[t]{2}{*}{$\mathrm{p}$} & \multirow[t]{2}{*}{$95 \% \mathrm{CI}$} \\
\hline & & Positive & Negative & & & \\
\hline \multicolumn{7}{|c|}{ Case $n=65$} \\
\hline \multirow[t]{3}{*}{ Age } & $\leq 59 n=11$ & $1 \quad(9.1)$ & 10 & 6.973 & 0.031 & \\
\hline & $60-69 n=29$ & $5(17.2)$ & 24 & & & \\
\hline & $\geq 70 n=25$ & $11(44)$ & 14 & & & \\
\hline \multirow[t]{2}{*}{ Sex } & Male $n=44$ & $15(34.1)$ & 29 & 4.442 & 0.035 & $9.381 .3-67.6$ \\
\hline & Female $n=21$ & $2(9.5)$ & 19 & & & \\
\hline \multicolumn{7}{|c|}{ Control $n=82$} \\
\hline \multirow[t]{3}{*}{ Age } & $\leq 59 n=39$ & $3 \quad(7.7)$ & 36 & 1.419 & 0.575 & \\
\hline & $60-69 n=23$ & $4(17.4)$ & 19 & & & \\
\hline & $\geq 70 n=20$ & $2(10)$ & 18 & & & \\
\hline \multirow[t]{2}{*}{ Sex } & Male $n=58$ & $4 \quad(6.8)$ & 54 & 3.375 & 0.066 & \\
\hline & Female $n=24$ & $5(20.8)$ & 19 & & & \\
\hline
\end{tabular}

and Roberts, 2010; Peng et al., 2012). In recent years, especially in Japan and the U.S incidence of many types of cancers are stable or declining but have increased substantially for HCC. Tanaka et al. (2002) stated that in Japan, the age-adjusted annual death rate due to primary liver cancer rose from approximately 10 per 100,000 in 1975 to 27.5 in 2002. This is attributed to increased prevalence of $\mathrm{HCV}$ infection.

Takano et al. (1997) reported that HCC remains a highly malignant tumour, with average survival rates after clinical onset of less than one year. The major problem of HCC treatment was that most patients of HCC were diagnosed at advanced stage of the disease. Clearly, the most practical approach to improve management of HCC is prevention and early detection (Savino et al., 2011). Globally HCV were considered as a significant risk factor in HCC development (Samreen et al., 2012; Peng et al., 2012). HCC progression varied among patients with chronic hepatitis $\mathrm{C}$, due to a complex interplay between host, viral and environmental factors (David et al., 2011) including older age at time of $\mathrm{HCV}$ infection, male gender, heavy alcohol intake and transfusion-related mode of HCV acquisition (Sherman, 2005; Savino et al., 2011; Jin-Hu et al., 2013).

Our study revealed that anti-HCV was significantly higher $(26.1 \%)$ among HCC patient. This finding is supported by other studies (Zhang, 1998; Jin-Hu et al., 2013) which reported that anti-HCV were significantly higher in HCC patients (27.7\% and $11.2 \%$ respectively) than in the control. Moreover, several authors reported that the prevalence of anti-HCV positives in HCC were $62 \%$ in Spain (Ruiz et al., 1992), 29\% in the U.S (Yu MC et al., 1990) and 70-90\% among Japanese (Nishioka et al., 1991; Takano et al., 1995). Variations of anti-HCV seropositivity levels in different countries could be attributed to population characteristics, drug addiction, alcohol consumption, homosexuality or mode of $\mathrm{HCV}$ transmission. Several scientists reported that Hepatitis C virus is the major causative agent of HCC, mainly through indirect pathways. Other clinical research indicated that $\mathrm{HCV}$ is directly involved in hepatocarcinogenesis (Koike, 2007; and Farinati et al., 2007; Abd El-Rhman et al., 2013). However, the mechanism of virus related carcinoma is not fully understood. It is clear that hepatitis virus alone or in conjunction with other environmental risk factors can contribute to the epidemiological clinical heterogeneity of HCC. This is also supported by a study in Japan which detected that $40 \%$ of HCC patients were anti-HCV seronegative (Nishioka et al., 1991). This study detected $73.84 \%$ of HCC patients anti-HCV were seronegative. This finding is confirmed by Esaki et al. (2004), suggesting that HCV-RNA was detected in liver

Table 3. HCV-RNA and Genotype Distribution Among HCC Cases and Patients with Other Malignant Disease (Control).

\begin{tabular}{|c|c|c|c|c|c|c|c|c|c|c|c|}
\hline \multirow{2}{*}{$\begin{array}{l}\text { Anti-HCV LiaTek III } \\
\text { positive subjects }\end{array}$} & \multicolumn{2}{|c|}{ HCV-RNA } & \multirow[t]{2}{*}{$\mathrm{X}^{2}$} & \multirow[t]{2}{*}{$\mathrm{p}$} & \multirow[t]{2}{*}{ OR } & \multirow[t]{2}{*}{$95 \% \mathrm{CI}$} & \multicolumn{5}{|c|}{ HCV Genotypes/subtypes } \\
\hline & Negative & Positive & & & & & $1 \mathrm{a}$ & $1 b$ & 4 & $1 \mathrm{~b}$ and 4 & Total \\
\hline Cases $n=17$ & 5 & 12 & 5.53 & 0.01 & 9.057 & $1.9-42.1$ & 1 & 5 & 3 & 3 & 12 \\
\hline Control $n=9$ & 7 & 2 & & & & & - & 1 & 1 & - & 2 \\
\hline Total $n=26$ & 12 & 14 & & & & & 1 & 6 & 4 & 3 & 14 \\
\hline
\end{tabular}


Waqar Abd Al Qahar Al-Kubaisy et al

tissue among HCC patients with negative HCV serology.

Jian-Ying et al. (1998) found that there was no significant association between HCV infection and HCC (OR=3.06; 95\% CI:0.46-20.24). However, our study revealed that HCC patients significantly had almost 3 times higher risk of exposure to $\mathrm{HCV}$ infection compared to the control group $(\mathrm{OR}=2.87,95 \% \mathrm{CI}=1.1-7)$. Our finding was confirmed by another two studies one done by Jin-Hu et al. (2013) in China which found that the RR was 13.1 for $\mathrm{HCV}$ infection among $\mathrm{HCC}$ patients and another study done by Donato et al. (2002) in Greece which found that HCC risk increases to 17-fold in HCVinfected patients compared to HCV-negative subjects (OR=6.3, 95\% CI=3.7-11). Moreover Jen-Eing et al. (2014) reported that $\mathrm{HCV}$ is an independent risk factor for $\operatorname{HCC}(\mathrm{OR}=28.57, \mathrm{p}=0.001)$.

High percentage $(71.6 \%)$ of our HCC patients demonstrated positive HCV-RNA in their sera, whereas $29.4 \%$ were HCV-RNA seronegative. This finding was supported by other studies which stated that patients developed HCC in spite of viral clearance, suggesting that $\mathrm{HCV}$ per se could have a direct oncogenic effect. This may be attributed to genetic mutation induced by HCV (Moutaz and Aliaa, 2009). As reported by Esaki et al. (2004), HCV-RNA was detected in liver tissue among HCC patients with negative HCV serology. He also strongly proposed the notion that HCV RNA might be expressed in the liver and extra-hepatic reservoirs in spite of the absence of circulating viremia. These virus may be active, and facilitated the development of HCC.

Our study showed that anti-HCV rate increased steadily with increasing age, supporting other studies (Savino et. al., 2011; Jen-Eing et al., 2014), who stated that HCC was age-related and the age distribution varies in different local regions globally. Several authors also found that older age ( $>55$ years) acts as independent factors associated with HCC progression (Sherman 2005; Hirakawa et al., 2008; Amal et al., 2011; Savino et al., 2011; Jen-Eing et al., 2014). This might be due to the fact that development of HCC usually occurs after two or more decades of HCV infection (Savino et al., 2011).

Many studies suggested male predominance in antiHCV positive HCC (Sherman, 2005; Savino et al., 2011; Jin-Hu et al., 2013; Abd El-Rhman, 2013; Jen-Eing et al., 2014). This was confirmed by our study which found a significantly anti-HCV seropositivity rate higher among males $(34.1 \%)$ compared to female patients. Our study also revealed that male HCC patients was more than 9 times higher risk of exposure to $\mathrm{HCV}$ infection compared to females $(\mathrm{OR}=9.38,95 \% \mathrm{CI}=1.3-67.65)$. Our finding was confirmed by Savino et al. (2011) and Sherman (2005) who claimed that male gender had 2-3-fold increased risk. This finding may be due to the fact that HCC always had androgen receptors (Kazuo et al., 1997) and males also usually have history of drinking alcohol and/or smoking (Jin-Hu et al., 2013; Jen-Eing et al., 2014).

HCV has high genetic diversity and has been classified into six major genotypes that differ in their geographical distributions and natural history (Farrell, 2002). Genotypes 1-3 are widely distributed worldwide (Sherman, 2005) and are prevalent in North and South America, Europe, and Australia (El-Serag, 2002). Globally, infection with genotype 1 is the most common (Rathi et al., 2011). Subtype $1 \mathrm{~b}$ is common in North America and Europe, and is also found in parts of Asia (Rivas-Estilla et al, 2008). In Iraq HCV- $1 \mathrm{~b}$ prevalence is next common to genotypes 4 (Al Kubaisy, 1998).

HCV genotype and viral load are two important prognostic variables, knowledge of which might be useful in the treatment decision (Anita et al., 2011; Jin-Hu et al., 2013) to eradicate HCV thus reduce and prevent HCC (Savino et al., 2011). The correlation between HCV genotypes and viral load remains controversial. Some studies reported that high titre viraemia was correlated with advanced liver stage (Berry et al., 2005) while others found no correlation. A study on the viral load found that genotype 1 was significantly higher than those with genotypes 2 and 3 (Anita et al., 2011; Rathi et al., 2011). This might be due to more efficient viral replication of genotype 1 as compared to the others (Anita et al., 2011). However, the severity of liver disease was more in genotype 1 as assessed by higher viral load (Anita et al., 2011). A recent meta-analysis of patients with liver cirrhosis strongly suggested that HCV genotype $1 \mathrm{~b}$ was associated with almost two times the risk of developing $\mathrm{HCC}$ than those infected with other genotypes (Parkin et al., 2005).

There was a conflict as to whether genotype 1 is a risk factor for HCC independent of old age (Willatt et al., 2008; Lok, 2011). Hirakawa et al. (2008), from their studies showed that genotype 1 was an independent risk factor for tumour development. Interestingly our study found that all HCC patients were harbouring only three different $\mathrm{HCV}$-genotypes with HCV-Ib as the most predominant, compared to HCV-4 which is more predominant among Iraqi population (Al Kubaisy, 1998). Similar finding was suggested by Nausbaun et al. (1995) and Fujioka et al. (2003) found that HCV-Ib is a major risk factor in patient with HCC. On the other hand, Moutaz and Aliaa (2009) reported that HCV genotype-4 act as direct oncogenic effect for development of HCC. This is because genotype-4 is highly prevalent in Egypt in addition to the co-existence of multiple risk factors and progression to HCC (Shiratori et al., 2000).

In conclusion, Our study detected a significantly higher rate of anti-HCV seropositivity in HCC patients. Hence, $\mathrm{HCV}$ infection acts as a significant risk factor of $\mathrm{HCC}$. HCC patients harbour a higher rate of $\mathrm{HCV}-1 \mathrm{~b}$ than control group.

This study had few limitations such as lack of the data on HCV viral load and it is retrospective study with a small number of patients. A prospective study with larger sample is needed to confirm our results.

\section{Acknowledgements}

We would like to thank the director and the staff of the four hospitals namely Baghdad Teaching Hospital Baghdad Medical City, Al Kadhmiya Teaching Hospital, Radiology and Nuclear Medicine Institute and Al Yarmuk General Teaching Hospital for allowing us to conduct the study. Special thanks to the patients who had consented 
to enable us to conduct the study.

\section{References}

Abd El-Rahman NZ, Nabawy Z, Auhood AMN, et al (2013). Disease progression from chronic hepatitis $\mathrm{C}$ to cirrhosis and hepatocellular carcinoma is associated with increasing DNA promoter methylation. Asian Pac J Cancer Prev, 14, 6721-26.

Aghemo A and Colombo M (2013). Hepatocellular carcinoma in chronic hepatitis C: from bench to bedside. Semin Immunopathol, 35, 111-20.

Al Kubaisy W (1998). Epidemiology and genotypic distribution of hepatitis $\mathrm{C}$ in Iraqi pregnant women. Thesis for degree of doctor in philosophy. Baghdad-Iraq.

Altekruse SF, McGlynn KA, Reichman ME (2009). Hepatocellular carcinoma incidence, mortality, and survival trends in the United States from 1975 to 2005. J Clin Oncol, 27, 1485-91.

Amal AM, Samah AL, James DC, Abdel Gawad MH, Ibrahem $S$ (2011). Chronic hepatitis C genotype-4 infection: role of insulin resistance in hepatocellular carcinoma. Virology $J$, $8,496$.

Anita C, Gaurav D, Vikas V, Amit PS (2011). Distribution pattern of $\mathrm{HCV}$ genotypes and its association with viral load. Indian J Med Res, 133, 326-31.

Berry V, Arora R, Paul P (2005). Hepatitis C-clinical outcome and. diagnosis. J K Sci, 7, 129-32.

Chayama K, Tsubota A, Kobayashi M, et al (1997). Pretreatment virus load and multiple amino acid substitution in the interferon treatment in patients with chronic genotypes $1 \mathrm{~b}$ hepatitis $\mathrm{C}$ virus infection. Hepatology, 25, 745-9.

David RM, Stanley ML (2011). Virus-specific Mechanisms of carcinogenesis in hepatitis $\mathrm{C}$ virus associated liver cancer. Oncogene, 28, 1969-83.

Denis S, Abdelouahid EK, Hanan G, et al (2012). Hepatitis $\mathrm{C}$ virus-related hepatocellular carcinoma: An insight into molecular mechanisms and therapeutic strategies. World $J$ Hepatol, 4, 342-55.

Donato F, Tagger A, Gelatti U, et al (2002). Alcohol and hepatocellular carcinoma: the effect of lifetime intake and hepatitis virus infections in men and women. $A m J$ Epidemiol, 155, 323-31.

El-Serag HB, Mason AC (2000). Risk factors for the rising rates of primary liver cancer in the United States. Arch Intern Med.;160 (21): 3227-30.

El-Serag HB, Rudolph KL (2007). Hepatocellular carcinoma: epidemiology and molecular carcinogenesis. Gastroenterology, 132, 2557-76.

El-Serag HB (2002). Hepatocellular carcinoma and hepatitis C in the United States. Hepatology, 36, 74-83.

Esaki T, Suzuki N, Yokoyama K, et al (2004). Hepatocellular carcinoma in a patient with liver cirrhosis associated with negative serum $\mathrm{HCV}$ tests but positive liver tissue $\mathrm{HCV}$ RNA. Intern Med, 43, 279-82.

Farinati F, Cardin R, Bortolami M, et al (2007). Hepatitis C virus: From oxygen free radicals to hepatocellular carcinoma. $J$ Viral Hepat, 14, 821-9.

Farrell G (2002). Hepatitis C, other liver disorders, and liver health: a practical guide. sydney: maclennan and petty.

Fujioka S, Shimomura H, Iwasaki Y, et al (2003). Hepatitis B virus gene in liver tissue promotes hepatocellular carcinoma development in chronic hepatitis C patients. Dig Dis Sci, 48, 1920-4.

Hirakawa M,Ikeda K, Arase Y, et al (2008). Hepatocarcinogenesis following HCV RNA eradication by interferon in chronic hepatitis patients. Intern Med, 47, 1637-43.

Hossein K, Mehdi F, Seyed HRM, Hamid RM (2012). Hepatitis
$\mathrm{C}$ virus-proteins, diagnosis, treatment and new approaches for vaccine development. Asian Pac J Cancer Prev, 13, 5917-35.

Jen-Eing J, Meng-Feng T, Hey-Ru T, et al (2014). Impact of hepatitis $\mathrm{B}$ and hepatitis $\mathrm{C}$ on adverse hepatitis fibrosis in hepatocellular carcinoma related to betel quid chewing. Asian Pac J Cancer Prev, 15, 637-42.

Jian-Ying Z, Min D, Xiao W, et al (1998). A case-control study of hepatitis $\mathrm{B}$ and $\mathrm{C}$ virus infection as risk factors for hepatocellular carcinoma in Henan, China. Int J Epidemiol, 27, 574-8.

Jin-Hu F, Jian-Bing W, Yong J, et al (2013). Attributable causes of liver cancer. Asian Pac J Cancer Prev, 14, 7251-56.

Kazuo T, Shoji T (1997). Relationship between the recurrence of hepatocellular carcinoma (HCC) and serum alonine aminotransferase levels in hepatoctomized patient with hepatitis $\mathrm{C}$ virus associated cirrhosis and HCC. Cancer, 79, 688-94.

Kew MC, Yu MC, Kedda MA, et al (1997). The relative roles of hepatitis B and C viruses in the etiology of hepatocellular carcinoma in southern African blacks. Gastroenterology, 112, 184-7.

Koike K (2007). Hepatitis C virus contributes to hepatocarcinogenesis by modulating metabolic and intracellular signaling pathways. J Gastroenterol Hepatol, 22, 108-11.

Levrero M (2006). Viral hepatitis and liver cancer: the case of hepatitis C. Oncogene, 25, 3834-47.

Lindenbach BD, Thiel HJ, Rice CM (2007). Flaviviridae: the viruses and their replication. in: knipe DM, howley PM, editors. fields virology. $5^{\text {th }}$ ed. philadelphia: lippincott-raven.

Lok AS (2011). Maintenance peginterferon therapy and other factors associated with hepatocellular carcinoma in patients with advanced hepatitis C. Gastroenterology, 140, 840-9.

Moutaz D, Aliaa A (2009). Hepatocellular carcinoma in hepatitis c genotype 4 after viral clearance and in absence of cirrhosis: two case reports. Case Report Cases J, 2, 7927.

Nelson PK, Mathers BM, Cowie B, et al (2011). Global epidemiology of hepatitis B and hepatitis $\mathrm{C}$ in people who inject drugs: results of systematic reviews. Lancet, $\mathbf{3 7 8}$, 571-83.

Nishioka K, Watanabe J, Furuta S, et al (1991). A high prevalence of antibodies to the hepatitis $\mathrm{C}$ virus in patients with hepatocellular carcinoma in Japan. Cancer, 67, 429-33.

Nousbaum JB, Pol S, Nalpas B, et al (1995). Hepatitis C virus type $1 \mathrm{~b}$ (II) infection in France and Italy. collaborative study group. Ann Intern Med, 122, 161-8.

Parkin DM, Bray F, Ferlay J, Pisani P. (2005). Global cancer statistics, 2002. CA Cancer J Clin, 55, 74-108.

Peng C, You C, Mei XS, et al (2012). Bicluster and pathway enrichment analysis of $\mathrm{HCV}$-induced cirrhosis and hepatocellular carcinoma. Asian Pac J Cancer Prev, 13, 3741-45.

Rathi PK, Lucinda LH, Lauren EE, Stanley ML, David RM (2011). Hepatitis C Virus Infection causes cell cycle arrest at the level of initiation of mitosis. $J$ Virol, 85, 7989-8001.

Rivas-Estilla AM, Cordero-Perez P, Trujillo-Murillo KC, et al (2008). Genotyping of hepatitis C virus (HCV) in infected patients from Northeast Mexico. Ann Hepatol, 7, 144-7.

Ruiz J, Sangro B, Cuende JI, et al (1992). Hepatitis B and C viral infections in patients with hepatocellular cardnoma. Hepatology, 16, 637-41.

Samreen B, Khaliq S, Ashfaq UA, et al (2012). Hepatitis C virus entry: role of host and viral factors. Infect Genet Evol, 12, 1699-709.

Sangiovanni A, Del Ninno E, Fasani P, et al (2004). Increased survival of cirrhotic patients with a hepatocellular carcinoma 
Waqar Abd Al Qahar Al-Kubaisy et al

detected during surveillance. Gastroenterology, 126, 100514.

Savino B, Daniela S, Piero LA, et al (2011). Critical reappraisal of risk factors for occurrence of hepatocellular carcinoma in patients with hepatitis C virus. Hepat Med, 3, 21-8.

Sherman M (2005). Hepatocellular carcinoma: epidemiology, risk factors and screening. Semin Liver Dis, 25, 143-54.

Shiratori Y, Imazeki F, Moriyama M, et al (2000). Histologic improvement of fibrosis in patients with hepatitis $\mathrm{C}$ who have sustained response to interferon therapy. Ann Intern Med, 132, 517-24.

Simmonds P, Alberti A, Alter HJ, et al (1994). A proposal system for the nomenclature of hepatitis $\mathrm{C}$ viral genotypes. Hepatology, 19, 1321-4.

Takano S, Yokosuka O, Imazeld F, et al (1995). Incidence of hepatocellular carcinoma in chronic hepatitis B and C: a prospective study of 251 patients. Hepatology, 21, 650-5.

Takeshi T, Kazuhiro N, Akiko S, et al (2012). Genetic risk of hepatocellular carcinoma in patients with hepatitis $\mathrm{C}$ virus : a case control study. J Gastroenterol Hepatol, 27, 797-804.

Tanaka Y, Hanada K, Mizokami M, et al (2002). Inaugural article: a comparison of the molecular clock of hepatitis $\mathrm{C}$ virus in the US and Japan. Proc Natl AcadSci USA, 99, 15584-9.

Tornesello ML, Buonaguro L, Tatangelo F, et al (2013). Mutations in TP53, CTNNB1 and PIK3CA genes in hepatocellular carcinoma associated with hepatitis B and hepatitis C virus infections. Genomics, 102, 74-83.

Willatt JM, Hussain HK, Adusumilli S, et al (2008). MR Imaging of hepatocellular carcinoma in the cirrhotic liver: challenges and controversies. Radiology, 247, 311-30.

Yang JD, Roberts LR (2010). Hepatocellular carcinoma: a global view. Nat Rev Gastroenterol Hepatol, 7, 448-58.

Yu MC, Tong MJ, Coursaget P, et al (1990). Prevalence of hepatitis $\mathrm{B}$ and $\mathrm{C}$ viral markers in black and white patients with hepatocellular carcinoma in the US. J Natl Cancer Inst, 82, 1038-61. 